\title{
INTEGRATED WATER RESOURCES MANAGEMENT: FROM A COMPLEXITY THEORY PERSPECTIVE
}

\author{
JOSÉ A. VÁSQUEZ \\ Faculty of Economical and Administrative Sciences, Universidad de Medellín, Colombia
}

\begin{abstract}
Taking into account the international literature on the subject, it is necessary to advance in terms of leading theoretical definitions to go beyond the existing theoretical and methodological currents of thought. Past research has approached the issues of water management in a fragmented way; that is to say, without considering the multiple interrelations with other natural resources such as the soil, fauna, plants, and human beings. This reveals the need for acknowledging the nature and complexity of water management by involving socioeconomic, cultural, governance, sustainability, ecological, geological and other concepts related to natural resources. The purpose of this paper is to show how, from a new approach named the time-concept, it is possible to represent things as interrelated complex phenomena experiencing constant changes (in development). Thus, it is aimed at proposing new conceptual water management alternatives that integrate the multiple relations between nature and culture, including the appropriation of water heritage. The central underlying assumption in the paper considers that comprehensive water management conceived from the integration of nature-culture relations would encourage a respect for the uniqueness of biophysical and social contexts (which are in constant transformation). This, in turn, would favour the protection of water resources as a heritage in all its manifestations on Earth. The consolidation of the relations between nature and culture is interpreted as an interaction that occurs between human beings and the environment (the biophysical environment); this happens through cultural practices related to the different forms of appropriation of water: use, improvement, respect, love and protection. The contribution of this research is centred on proposing an alternative approach to an integral water management model from a complexity perspective; it would lead to studying water-related subjects in an interrelated and progressive way.
\end{abstract}

Keywords: water resources management, complexity theory, concept-time.

\section{INTRODUCTION}

Water management models that emerged between the eighteenth and twentieth centuries have been based on the modern sciences: natural (physics, chemistry, geology, hydrology, biology, and their applications, techniques and engineering) and social (anthropology, sociology, economics, among others). Simultaneously, these sciences have been built starting from the paradigm of scientific knowledge (based on the analysis), which supposes the separation between the natural sciences and the social sciences. Therefore, the administration of water from such models inherits this fragmentation, which does not support the concept of the relationship between nature and culture (natural and social sciences) as forming a single unit, in the processes of decision-making related to the management of water. However, the management of water suggests the competition of various sciences and/or disciplines, as proposed by Dourojeanni [1]; quoting Rölling [2], "the instrumental-economic solutions have led to the human beings to deal with the environment and to pillage it and these will not be the only ones that will allow to overcome this dilemma, in fact those solutions have been the ones that have created the environmental degradation."

As a result of the use of models for water management that have emerged between the eighteenth and twentieth centuries, several problems have arisen, particularly in the last two decades in the world, for both the natural heritage - biotic and abiotic - and human 
communities, which could be summarized in accordance with the Declaration of new Culture [3] as follows: "The ecological crisis of aquatic ecosystems; the unsustainable exploitation operation in many aquifers; the growing problems in the quality of those resources; problems of inefficiency and economic irrationality; problems of governance due to the lack of transparency and citizen participation.” These consequences for the natural environment, and communities in general, have caused a crisis in the various approaches to the management of water in the world, which has led to the emergence of other alternatives for the management of water. The priority of water for the sustenance of life on earth implies the need to think of management alternatives that transcend these environmental problems caused as a result of its administration. In accordance with Dourojeanni [1], management on a more holistic approach, that induces the possibility to overcome such problems, involves "having the ability to properly manage natural elements such as water, forests, fauna or to entire ecosystems." In this direction, it is possible to identify, on a global scale, a multidimensional alternative that adopts a multidimensional approach for the administration of water - the integrated management of water resources (Integrated Water Resources Management, IWRM). In accordance with Mayfield and Gover [4], this approach or model arose between the 1970s and 1980s as an answer to the sectorial management of water, and it has spread across almost all the world, particularly in Latin America, as the Economic Commission supports it for Latin America and the Caribbean Sea (CEPAL) [5]. In accordance with the International Water and Sanitation Centre (International Center of Drinking water and Sanitation, IRC), quoted by the Department of Environment of Colombia [6], the integrated management of water resources appeared as an answer to the "crisis of the water" expressed in the untenable pressure on water resources, due to the increasing demand for water, and an increase in contamination and population.

In relation to the models of water management that have emerged between the eighteenth and twentieth centuries (end of the twentieth century), which have been conceived from an epistemological approach, they make it more difficult to think of topics such as the composition of the relationship between nature and culture, which acquire a significant relevance and a more holistic and multidimensional approach to the integrated management of the resources. In this regard, in accordance with the Global Water Partnership (GWP), "the integrated management of resources is an approach of intersectoral policy, intended to replace the traditional approach, the sectoral fragmented approach in water resources and management that has led to the poor service and the unsustainable use of resources." Following the GWP [7], this concept is based on the understanding of water resources as an "integrated component of the ecosystem, a natural resource and a social and economic good.”

\section{INTEGRATED WATER RESOURCES MANAGEMENT}

Calcagno [8] identifies two models of IWRM at the international level, proposed by various multilateral organizations: the GWP and the Inter-American Development Bank (IDB). For the GWP [9], "integrated water resources management is a process that promotes the management of coordinated development of water, land and resources, in order to maximize the resultant economic and social welfare in equitable mode without compromising the sustainability of vital ecosystems". On the other hand, for the IDB, "it is the set of activities or projects to enhance the conservation of water and to use it more efficiently, increasing the complementarity in both quantity and quality, or reducing the conflicts between usages that compete, in a given sector or between subsectors. This includes the management of the supply and demand and encourages the existence of 
relevant organizations, regulatory frameworks and human resources” (Calcagno [8]). In accordance with Rahaman and Varis [10], in 2002 the GWP adopted some guiding principles for the IWRM that have found universal support through the international community.

This study will address the management of water in light of the model of IWRM provided by the GWP for several reasons; it is a more holistic and multidimensional approach, it has had a level of acceptance at the global level (particularly in Latin America), and it has the potential to reframe the management of water and provide alternative solutions to the problem of deterioration of water patrimony.

In accordance with Dourojeanni [1], the strengths of the integrated management of water resources are derived from three basic issues in water management: "a) it claims the importance of water as a fundamental good for sustaining life; b) it recognizes the water management must be based on a participatory approach, which will involve users, planners and policy makers.” Dourojeanni [1], in this sense, raises an idea which essentially aims to minimize conflicts between users. Following Dourojeanni, an essential aspect is the following: water management is the management of conflicts between usages considering the limitations of nature (from water and the natural environment in general). Finally, “c) integrated water management intends to build a multidimensional approach of water management, which allows thinking of a way to manage the water, considering the integration of nature and culture" (Dourojeanni [1]).

Although the integrated management of water resources has been adopted by the international community for years, it presents a major constraint, "it lacks from a theoretical construct that might be a support for that approach to management under the principles of the Global Water Partnership” (Mayfield and Gover [4]). This theoretical basis would also guide the decision-making processes in various matters to conceive the model, meaning to define what and how to integrate the elements in the IWRM; hence, to determine how to schedule the IWRM, how to develop capacity for IWRM, how the organizational management for IWRM should be developed, how to develop capacity for IWRM, and, finally, how to implement the model. On the other hand, according to Dourojeanni [1], "there is not a definitive course nor theoretical or conceptual framework to achieve consensus on the options to improve the management of water."

\section{WATER MANAGEMENT, INTERDISCIPLINARY NATURE AND COMPLEXITY}

The integrated management of water seeks to achieve the maximization of the social and economic welfare in an equitable mode; this suggests the need to think simultaneously about the natural and social aspects, as well as about the relationship between ecosystems and culture. In addition, this approach to management refers to the management of the water resource without compromising the sustainability of vital ecosystems, which induces thinking in such a way that considers the sustainability of ecosystems over time.

Assuming that the ways of use, protection and improvement of water resources are a matter determined by the forms of human appropriation of water (through the use of technology, science, customs and, in general, codes of the culture), the state of the natural resources in the territory, in a place and space of time, is the result of the interaction between man and nature, and, more broadly, culture and nature. These relations of interdependence are subject to changing circumstances through time, which imply support for the concept of uncertainty, both in human actions and in the state of resources in nature. This situation allows us to consider the need to conceive, simultaneously, certainty and uncertainty, chaos and order. To conceive the integral management of water from the perspective of nature-culture interaction, we need to think of the phenomena from an 
interdisciplinary standpoint rather than from a specialized science, considering economics, biology, hydrology, geology, sociology, as it is often discussed in the studies related to the management of water, in the light of the analytical paradigm, according to which ecosystems are designed as fragmented sets, conformed by isolated parts.

In accordance with Dogan [11], the term interdisciplinarity suggests a multidimensional concept of the phenomena and the relative character of scientific approaches separately. Basically, it relates to the integration of the theories, methods, instruments and, in general, scientific actions of different disciplines from a multidimensional concept of the phenomena. On the other hand, for Rozo [12] interdisciplinarity is, in general, a term related to the meeting of different disciplines in order to address the treatment of a phenomenon (of great complexity) that resists being apprehended by a discipline exclusively. In this regard, it suggests transcending the approach towards the study and understanding of the phenomena from a science, discipline or area of specialized knowledge perspective, and assumes that specialized knowledge does not allow for the full approach to the reality of the phenomena, and, therefore, there is a contest of diverse areas of the knowledge for the apprehension, analysis and comprehension of the phenomena. Stating this, it resorts to the methods and procedures of modern science, since it recognizes the limits of existence between the sciences and the distinction of different objects of knowledge in each knowledge area.

Although it allows for a more holistic view of the phenomena, the interdisciplinarity approach is based on the idea of the separation between sciences, and sees the world as a sum of parties, whose integration is the whole. Although this approach is more rich and diverse than the specialized science, and even proposes a way to overcome the reductionism of modern science, it adopts an analytical approach, with the insulation of the objects of knowledge of the context and, therefore, maintains the separation nature culture that proposes the modern science. With this in mind, this perspective of knowledge does not provide elements for thinking about the world of life as it really is, which is complex, and subject to uncertainty, unpredictability and to the interconnections and frames that are held in nature.

Addressing the integrated management of water in its complex dimension, in permanent relation to other natural resources, demands an extension of the approach of analytical thinking and interdisciplinarity towards other ways of approaching the phenomena that support the rethinking of the fragmentation of the world in science, knowledge or other disciplines. This implies the consideration of multiple relationships that underpin both nature and culture. In this regard, if the interconnected natural resources (partners) are considered within the Integral Management of Water, there emerges a need to think about the management of water from a perspective that supports designing water resources and other natural resources in permanent connection, as suggested by the general theory of systems.

The integral management of water, by its nature, demands a perspective of knowledge that supports the linking of factors of biophysical, social, cultural, economic, historical, political order, among other issues; considering their relationships and continuous interaction. In an ecosystem, these factors are interrelated in various ways constituting a special type of complex system, whose behaviour in time is somehow unpredictable, contradictory and against intuitive approaches. In this regard, in accordance with Brugué et al. [13], "the main problem is in the contrast between the simplicity of our administrations and the complexity of the problems to be resolved. The classical administrative modus operandi is, precisely, to simplify the problems, reducing them to a specialized field capable of dealing them with their sectoral expertise. The current reality, however, does not 
seem to accept these simplifications, is too complex, sophisticated and diverse to be subject to the restrictions of a partial understanding; and it is here where is the main challenge for the public interventions. Some interventions that have been built based on logical sectoral applied to one dimensional problems and from that nowadays it must be learnt to provide multisectoral responses to multidimensional issues.” Probing for a rapprochement between the behaviour of complex systems suggests necessarily adopting an approach of reflection that transcends determinism and a forecast that characterizes scientific knowledge and modern science. The previous statement suggests the need to consider the theories of complexity and the complex understanding posed by Morín [14], where it is necessary to address the issues concerning the integral management of water. If it is recognized that this is not possible from the scientific paradigm and the method of analytical thinking, the study and understanding of the phenomena in their complexity dimension, and in view of the fact that this paradigm and the analytical method cannot conceive of the net of relationships that gives rise to the emergence of the phenomena (since the objects of knowledge are considered in isolation), there arises the need for an approach of thought that transcends these challenges, with a view to build other ways of thinking about the integrated management of water.

For Maldonado [15] the complexity itself of a phenomenon lies, therefore, in the fact that its dynamics and structures cannot be reduced to explanations or efforts of a cyclical, periodical, regular or predictable nature; "a complex phenomenon is one that displays properties of adaptation and learning as a result of inflections - unforeseen and dramatic by definition. It is worth to say that not all systems or phenomena learn or adapt." For Maldonado [15] the complexity requires and affirms a philosophy of movement, in the sense that the complex systems (of growing complexity) are characterized, mainly by presenting irreversible, sudden, unforeseeable non-periodic dynamics; moreover, several other characteristic features. For Rozo [16] complexity comes from the Latin complexus, that means "what is woven together. The complex analysis distinguishes without disengage, analyzes without fractionate, includes/describes systemic units in their multiple interrelations, connections and possibilities.” This complex understanding leaves behind deterministic ideas and the notion of order by the complementarities. With this, the notions of contradictories do not reject disorder and organization, nature-culture, tangible and intangible, subject-object. For Morín [14], "The complexity is a net of heterogeneous inseparably constituents associated.” And quoting Morín [14], he suggests that something that is complex retrieves, on the one hand, the empirical world, uncertainty, the inability to achieve certainty, to formulate a law to devise an absolute order.

According to Maldonado [17] it is possible to recognize complexity from three aspects: complexity as method, proposed by Edgar Morin (1992, 1994, 1998, 1999, 2003, 2004, 2006) and his followers, known as the Complex Thinking; complexity as a worldview, that brings together several authors, among them, Capra [18], von Bertalanffy (1976), von Foerster (1978, 1984, 2003), Maturana and Varela (1980, 1992, 1996), Bateson (1985, 1993) and, in general, all the school of Palo Alto, in California; complexity as science, which includes Nicolis and Prigogine (1987), Wallerstein (1987, 2004), Prigogine (1983), Maldonado [17], and the works of theorists and researchers at the Santa Fe Institute in New Mexico (US), and, in general, the Free University of Brussels in Belgium. Within this paper, integral water management will be addressed from the complexity of the perspective of complex thinking. 


\section{INTEGRATED WATER MANAGEMENT FROM THE PERSPECTIVE OF COMPLEXITY}

Conceiving the phenomena in light of complex thinking is another way of conceptualizing, which will be built on the basis of the following approaches: (a) the recognition of the relationship as a central element for the emergence of the phenomenon, meaning that the phenomena does not exist previously but that emerges continually; (b) the declaration of the nature of uniqueness and specificity (or better dialectics of the concrete), which possesses the phenomena, in place of generality and abstraction - is usually refers to the concept that suggests modern science in which each phenomenon is unique and unrepeatable and, therefore, you cannot define or conceptualize in a general manner; and (c) the recognition of the change in time that continuously assists the frame network of relationships (dynamics), which gives rise to the emergence of the phenomena (in this case, of water as a phenomenon). The latter refers to the phenomena that is always determined by change, which represents that no phenomenon is permanent and unchangeable. Considering this approach, the following section presents a way of conceiving water management from a standpoint of complexity that supports the reintegration of the nature-culture relationship and, therefore, the concept of integrated water to the other components of the ecosystem, as a single unit. This raises the notion of concept-time, a redefinition of the notion of a concept, built in order to transcend the concept of modern science. Subsequently, some principles are raised to guide the construction of concepts and finally some ideas are proposed to address, from the concept-time approach, integrated water management.

\subsection{Concept-time}

Concept-time is a singular and pseudo-concrete alternative of a phenomenon, object, or thing, whose definition emerges from a frame network of relationships that configures the imagination from the given (collection of prints and images, catalogue of perceptions) in the context or a specific place (particular). Concept-time aims to capture the phenomenon in a space-of-time gap between the past and the future. Therefore, this representation is continuously being discussed between what has been and will be in the future the frame network of relationships that gave rise to its existence. That is to say, its existence is subject to evolution.

Concept-time is defined as pseudo-concrete according to Kosik [19]; in the first place, because it derives from another different approach to learn which emerges as not entirely clear, and secondly because it is away from the idea of abstraction, since its existence and sense emerge from the frame network of relationships that is configured in a specific context.

Concept-time does more than express the essence of a thing; it aims to recognize it in its complexity, emerging from a fabric of relationships, which implies that the phenomenon, the object, the thing, among others, are not entirely clear and distinct. And, therefore, it is not intended to quote it clearly, to identify its essence. As a result, it supports the absence of complete information, as the existence of uncertainty at the time of design, and represents the phenomenon of water.

Since concept-time is emerging from the experience, it suggests we recognize the sensitive experience. This leads us to think that it refers to an idea of the phenomenon, object, or an abstract thing as already existing. The phenomenon emerges from the context and, therefore, it does not make sense for it to be conceived outside of it. For this reason, every phenomenon is unique and unrepeatable, like its conceptualization. 
Similarly, it refers to a singular by opposition to the idea of general representation, which suggests the traditional notion of concept. In this case, the idea of singular suggests that this is not a general phenomenon, which can be abstracted by their relations and interconnections with the environment, and whose significance is the same independently of the context from which it emerges. This is to recognize the unrepeatable character of the phenomenon, with which the category of general is not relevant to make reference or refer to it, since it would change its nature.

This idea of concept implies the representation of the phenomenon (in this case, of water) continuously subject to change, and, therefore, the uncertainty in terms of its existence or permanence in time, because it is a concept in transformation.

This notion of the concept is intended to access the "reality" directly in its concrete singularity. This implies that there would be no difference between theory and practice, since the phenomenon is conceived as an emergence of access to the concrete reality, rather than as a result of a process of abstraction (as frequently argue the theories of knowledge). Therefore, this notion is away from the traditional idea and abstract concept.

For the construction of the concept-time of a phenomenon, the following are a series of elements or principles: the principle of causation, refers to the phenomena, objects, things, which emerge from a frame network of relationships, rather than a single cause, with which the linearity and determinism are insufficient to capture the phenomenon. In this sense, it is not relevant or supports the insulation of the thing, through a process of abstraction, since that would induce its disfigurement. In this sense, the water, the concept-time of water in a community is the result of a multiplicity of relationships between the ecosystem and the culture of the population. The identity principle suggests that the phenomenon has a character of uniqueness that makes it unrepeatable and unique. With this, think the phenomenon from the generalization that is not relevant, because it induces to conceive from some level of universality in the nature of the phenomenon; that is, to assume that the frame network of relationships that gave rise to the emergence of the thing is immutable and is repeated in the same way in other contexts. In light of this principle the conception of water from each community is unique, unrepeatable and incomparable with the notion of water in other regions or latitudes. The principle of exteriority makes reference to a central issue of the concept and relations. In light of this principle is the relationship between the terms (objects, perceptions) which are not necessary and are a creation of the imagination. It is assumed that the relationship is not a property of the objects, the phenomena or things, but it is always outside of its terms. Unlike modern science, under whose perspective relationships are fundamental to explain or understand the phenomena (being necessary). Under the principle of exteriority, the relationship is first and foremost an act of continuous creation. With this, the relationships that are constructed on the basis of the given (pictures, perceptions) allow conceiving, in a way, the world of life. Since relationships are not necessary, it is not possible to determine with certainty what will be configured or the relationships, nor even less what will emerge from a frame network of relationships. This is why the concept-time involves considering uncertainty as a central component in the definition of a phenomenon. This principle allows us to consider that the relationships that the community builds with water could and obviously are changing over time, and are, therefore, not permanent. The principle of immanence refers to the phenomena, objects or things that emerge, and are not above, below, or comparable among them, with which it is not conceived the transcendence, superiority or the domain of some over others. Consistent with this, the concept-time of a phenomenon that emerges in a specific context will not be transcending to another concept-time of a phenomenon similar or different, regardless of the context or the time. With this principle it is possible to admit 
that the concept-time of water from a community is not better or worse, upper or lower than another, because they are not comparable, in view of the fact that each concept-time of water is unique and unrepeatable. In light of these principles, the integrated management of water in each community will, therefore, be unique, incomparable in continuous change and always dependent of the cultural context, due to those same singularities.

\subsection{The concept-time of water by mode of illustration}

On the basis of the suggested principles for the construction of the concept-time, we now consider the case of the phenomenon of water in a specific context - the basin of the Chico River in the State department of Antioquia (Colombia). This case study initially looks at the concept-time of water in light of the principles outlined above and following the concept-time for the integrated management of water.

Starting from the frame network of relationships that a community of the basin of the river has built around the water (principle of causality), water is conceived as a heritage provided by God for the service of man, animals and nature in general; determining factors for the construction and maintenance of the relations of affectivity among the inhabitants of the region; source for the provision of food (fishing) and recreational space of the local community. According to its flow in the channel, it is considered as a source premonitory of events in the future for the community. The concept of water that has emerged in the community of the basin has a unique character that makes it unique and unrepeatable (principle of identity), which does not support comparison with that which represents the phenomenon of water to another community, which could constitute a natural resource provided to man as a source of energy, for agricultural production and the human supply.

The frame network of relationships that allows the emergence of the phenomenon of water for this community (in its particular context), has been derived from processes of partnership and creation of the imagination, which could also have been different (principle of exteriority), as could be considered for the community in which the river is a source for the disposal of industrial waste. These relationships arise from the need of man to understand or explain the world, are determined by biophysical conditions and emerging cultural contexts and, therefore, constitute contingent forms (arising from circumstances unique and unrepeatable) from which the human being in their daily practice resolves life. In both cases, the concept-time of the phenomenon is a continuous subject to what has gone before and what may be in the future, subject to change or transformed on the frame network of relations which have emerged. This concept-time water is not comparable to others, it is not better nor superior, nor is more or less pertinent than others. In light of the principle of immanence, this concept-time of water, for the community of the basin of the Chico River, is not comparable with other concept-times of water, even current, in other regions or latitudes that have existed previously or that could exist in the future. In accordance with the principles entitled and identified, the concept-time of water in the community of the Chico river is unique, unrepeatable, derived from an unusual context and, therefore, needs a unique model for the integral management of water resources, which is relevant to the conceptualization of water that has built within the population. This management model, like the concept-time of water, will be continuously subject to change.

\subsection{Concept-time and integral management of water}

On the basis of the concept-water-time emerging in the community of the basin of the River Chico, the integrated management of water suggests thinking in an administration that is 
derived from the recognition of the phenomenon of water as an appearance of a frame network of relationships, unique (single), unrepeatable, that take place in a context and specific conditions. This implies recognition of the spiritual dimensions, mythological, social and cultural development of water, as well as the environmental services that it provides to the other components of the ecosystem. In this way, the management of the river water requires means for the protection and defence of their unique character, as forms of use and control systems tailored to the particular conditions that represent the source for the community and the physical and biotic environment. Thus, the concept-water-time suggests a new concept-time of integrated management of water and, in this way, the occurrence of other concept-times: planning, organization, direction and control, relating to water management, which will be oriented to the central basis to respect and protect the conditions that are determined in the frame network of relations that have been built in the community around the water.

In terms of integrated water management, the planning concept-time considers the use, protection and improvement of water in the basin as in permanent change, both at the physical level (quality and quantity), as well as for the collective imagination, in the frame network of relationships and in its continuous metamorphosis. The organization concepttime suggests the definition of some functions and structure non-permanent members in potential to adjust to changes in biophysical and cultural context. The management concepttime refers to a continuous guidance of the people towards the achievement of the proposed objectives, which, in turn, are exposed to changes in the context and the structure. The control concept-time refers to the adoption of measures and instruments which comply permanently with the change of the contexts biophysical and cultural. In this way, the regulations relating to the control of the use of water should be adjusted to the specific conditions of the community in the basin. There will, therefore, be no place to assemble norms for the use of water, independent of its context, as is usually done by simplification in most countries. Similarly, technologies for the control of the use and protection of water will be defined for the specific context. This implies the possibility of using eco-technologies developed and tested by communities.

By this unique character of each concept-time of water, the conception of the phenomenon from "similar" situations, implying a frame network of "similar" relationships (in general terms of non-existence) is not admissible; in other contexts, it would not be considered realistic to use their representation as a referent to think about the possible emergence of the phenomenon in other situations. That is to say, it is not appropriate to go to the generality and abstraction, to represent and think the phenomenon of water, and to therefore devise ways to manage it. In this regard, each system, model or mode of integrated management of water will have a unique representation, and this will also work, in different ways (possibly unique), to solve in each case the various problems associated with the water.

\section{CONCLUSIONS}

Concept-time constitutes a way to move beyond the generic and abstract conceptualization of the phenomena that permeates modern science, which makes it possible to conceive of the phenomena from its concrete, unrepeatable, and unique singularity.

In its potential to capture the phenomena in their complexity dimension, concept-time constitutes an alternative to transcend diverse problems that hinder a more holistic vision of water management. 
Concept-time suggests an alternative to capturing the phenomenon of water in its complexity dimension, emerging from a frame network of relationships within nature and culture. It allows us to consider methods of integrated water management that transcend the generality and abstraction which permeates the traditional models for the management of water. It is, therefore, possible to devise ways of water management that are relevant to the specific conditions of each context.

\section{REFERENCES}

[1] Dourojeanni, A., Desafíos para la gestión integrada de los recursos hídricos. Policy and Institutions for Integrated Water Resources Management, International Water Resources Association (IWRA), 2001.

[2] Rölling, N., Gateway to the global garden: Beta/gamma science for dealing with ecological rationality, University of Guelph, Ontario, Canada, 2000.

[3] Declaración Europea por una Nueva Cultura del Agua - DENCA, 2005, www.unizar.es/fnca/euwater/docu/declaracioneuropea.pdf. Accessed on: 10 Oct. 2015.

[4] Mayfield, C. \& Gover, V., Introduction to Integrated Water Resource Management, UN-Water Virtual Learning Centre, United Nations University: UNU-INWEH, UN Department of Economic and Social Affairs, 2008.

[5] CEPAL, Políticas Públicas para el Desarrollo Sustentable: La gestión integrada de cuencas. Parte I. Bases conceptuales y evolución de la gestión de cuencas, 1994.

[6] Ministerio de Ambiente Vivienda y Desarrollo Territorial, Política Nacional para la Gestión Integral del Recurso Hídrico (documento final), Bogotá, Colombia, 2010.

[7] Global Water Partnership (GWP) \& International Network of Basin Organizations (INBO), Manual para la Gestión Integrada de Recursos Hídricos en Cuencas, 2009. http://www.gwp.org/Global/ToolBox/References/. Accessed on: 26 Nov. 2015.

[8] Calcagno, A., Gestión Integrada de Recursos Hídricos Principios y estrategias. Universidad de Buenos Aires. Secretaría General de Ciencia y Técnica, Instituto Argentino de Recursos Hídricos. Bs. As., 2000.

[9] Global Water Partnership (GWP) \& Technical Advisory Committee (TAC), Background Paper No. 4: Integrated Water Resources Management, Estocolmo, 2000.

[10] Rahaman, M. \& Varis, O., Integrated water resources management: Evolution prospects and future challenges. Sustainability: Science, Practice \& Policy, 1(1), 2005.

[11] Dogan, M., “Interdisciplinas”, Revista Relaciones, Montevideo, Uruguay, No. 157, pp. 16-18, 1997.

[12] Rozo, G.J., Sistémica y Pensamiento Complejo. II Sujeto, Educación, Transdisciplinariedad. Fondo Editorial Biogénesis. Medellín, Colombia, 2004.

[13] Brugué, Q., Canal, R. \& Payá, P., Inteligencia administrativa para abordar problemas malditos? (El caso de las comisiones interdepartamentales). Revista Gestión y Política Pública, XXIV(1), pp. 85-130, 2015.

[14] Morín, E., Introducción al Pensamiento Complejo, Gedisa Editorial, España, 1998.

[15] Maldonado, C.E., Qué es un sistema complejo? Revista Colombiana de Filosofía de la Ciencia, 14(29), pp. 71-79, 2014.

[16] Rozo, G.J., Sistémica y Pensamiento Complejo. I Paradigmas, Sistemas, Complejidad, Fondo Editorial Biogénesis. Medellín, Colombia, 2003. 
[17] Maldonado, C., La complejidad es un problema no una cosmovisión. UCN Revista de Investigación, (13), pp. 42-54, 2009.

[18] Capra, F., La Trama de la Vida. Una Nueva Perspectiva de los Sistemas Vivos, Anagrama: Barcelona, 2006.

[19] Kosik, K., Dialéctica de lo Concreto, Estudio Sobre los Problemas del Hombre y el Mundo, 7th ed., Editorial Grijalbo SA: México DF, 1967. 